\title{
Why Are the Disabled People Willing to Participate in Sports: Taking Chinese Disabled Table Tennis Players as the Object of Investigation?
}

\author{
Jiandong Zhou ${ }^{1,2}$, Feng Yuan'2, Tao Yu², Futao Liu² \\ ${ }^{1}$ College of Education, Shandong Normal University, Jinan, China \\ ${ }^{2}$ College of Physical Education \& Sport, Shandong Normal University, Jinan, China \\ Email: "514908607@qq.com
}

Received 14 March 2016; accepted 2 May 2016; published 6 May 2016

Copyright (C) 2016 by authors and Scientific Research Publishing Inc.

This work is licensed under the Creative Commons Attribution International License (CC BY).

http://creativecommons.org/licenses/by/4.0/

(c) (i) Open Access

\section{Abstract}

In this paper, questionnaire survey and data analysis are the main research methods. Its main purpose is to try to answer the question "why are the disabled people willing to participate in sports" and to explore some of the important factors that affect the participation of persons with disabilities. The object of the study is the 83 disabled table tennis players in the national training base. "Questionnaire of Motivation Adapted Athletes (AQAM)" is an international standard. Through descriptive analysis and independent sample $T$ test data analysis, this study concludes three points: 1) "enhancing physical fitness", "loving table tennis sport" and "winning the respect of others" are the main reasons that contribute to the participation in sports of disabled persons; 2) The motives of male and female athletes with disabilities to participate in sports are quite different; 3) The sports participation motivation of persons with disabilities is positively related to their family circumstances.

\section{Keywords}

Participation Motivation, Psychology, Disabled People, Table Tennis Players, China

\section{Research Background}

In recent years, China's disabled athletes in the competition both at home and abroad have achieved very good results of the competition. As we know, if athletes with disabilities want to achieve better results than the normal

"Corresponding author.

How to cite this paper: Zhou, J. D., Yuan, F., Yu, T., \& Liu, F. T. (2016). Why Are the Disabled People Willing to Participate in Sports: Taking Chinese Disabled Table Tennis Players as the Object of Investigation? Advances in Physical Education, 6, 88-98. http://dx.doi.org/10.4236/ape.2016.62010 
athletes, they need to pay more efforts. Why are these disabled athletes so obsessed with sports under great pain? Why do they choose such tough and boring life style? These questions have been studied by some Chinese scholars (Zhang Junxian, 2008; Yu et al., 2009, etc.), but the researchers pay more attention to the theoretical analysis and seldom focus on the analysis of the psychological motivation of the disabled. In order to find the reasons behind these problems, this article collects a lot of survey data through questionnaires and interviews with the disabled athletes and the head coach Yuan Feng gives me lots of assistance and guidance.

\section{Research Subjects and Methods}

\subsection{Research Subjects}

We chose 83 disabled table tennis players in "The National Disability Training Base" in Shandong Normal University, Jinan, China. Among them, 45 males, 38 females; age range 14 - 41 years old. It must be noted that all of the research subjects are not sampled. These athletes are selected from all over the country and unified management in the "Training Base" from June 2014 to May 2015. Some of these disabled athletes are born with congenital disabilities, and some are acquired.

\subsection{Research Methods}

Documentation: To provide the necessary theoretical support and reference for this research, through the research on the psychology of the disabled, the sociology of the disabled, and the sports participation of the disabled.

Questionnaire survey: "Questionnaire of Motivation Adapted Athletes (AQAM)" questionnaire was used to investigate and analyze the questionnaire in the world. The whole questionnaire consisted of 30 questions. The first 10 questions were about the basic situation of the respondents, and the following 20 questions about his/her participation in the continuous movement of the various related factors. Each motivation problem (MQ) is the use of the weight of the weight of the type: five points on behalf of the highest motivation, one points on behalf of the lowest motivation. A total of 81 questionnaires were collected, and 73 of them were effective, which accounted for $52.05 \%$ of men, women accounted for $47.95 \%$, and $61.7 \%$ of the respondents had more than one year of national team training and competition experience.

Interview method: On the basis of the questionnaire survey, the individual is very characteristic of the disabled athletes to carry out in-depth interviews. The number of interviews for 10 world champions and they are very good representative of the disabled athletes.

Statistical method: Using the software of SPSS17.0 to carry out the effective questionnaire to carry on the mathematical analysis, mainly uses the principal component analysis, the general frequency statistics and the multidimensional frequency statistics, etc.

\section{Research Results and Analysis}

\subsection{The Extraction of Principal Components of Athletes Training}

\subsubsection{Male Disabled Athletes}

According to the method of extracting the number of principal components, the method of extracting the characteristic values of the characteristic values is more than 1 (see Table 1). Therefore, 5 main components are extracted in Table 2.

1) The component "Enrich their lives" (0.724) associated with the highest coefficient, reflecting the male athletes want to make rich and colorful life through sports training activities to improve the quality of life expectancy. Therefore, this factor is named "Enrich their lives factor".

2) The component "Contribute to the cause of disabled" (0.655), reflecting the desire of male athletes think through their own efforts to win honor for disabled person. Therefore, this factor was named "Contribute to the cause of disabled factor".

3) The component "Respect for others" (0.603), reflecting the urgent need to give disabled athletes as the tendency of social identity. Therefore, this factor is named "Respect for others factor".

4)The component "Improve living standards" (0.570), reflecting the male athletes with disabilities through sports training achievements hope to exchange future aspirations for a better life. Therefore, this factor is named "Improve living standards factor". 
Table 1. Main components of male athletes training motivation, contribution rate.

\begin{tabular}{ccc}
\hline Main Ingredients & Characteristic Value & The Contribution Rate (\%) \\
\hline 1 & 5.275 & 30.679 \\
2 & 3.869 & 18.375 \\
3 & 1.524 & 17.342 \\
4 & 1.135 & 9.627 \\
5 & 1.122 & 5.094 \\
6 & 0.916 & 5.076 \\
7 & 0.902 & 4.335 \\
8 & 0.864 & 4.311 \\
9 & 0.751 & 4.102 \\
10 & 0.640 & 3.654 \\
11 & 0.433 & 1.587 \\
12 & 0.281 & 1.332 \\
\hline
\end{tabular}

Table 2. Male athletes’ training motivation principal component features.

\begin{tabular}{cccccc}
\hline Component & Feature Vector 1 & Feature Vector 2 & Feature Vector 3 & Feature Vector 4 & Feature Vector 5 \\
\hline Contribute to the cause of disabled & -0.065 & 0.212 & 0.321 & 0.354 & 0.655 \\
No purpose & 0.182 & -0.661 & 0.071 & 0.269 & -0.238 \\
Exercise & 0.409 & 0.230 & -0.772 & 0.120 & 0.467 \\
Cater for their interests & 0.419 & 0.406 & -0.295 & 0.039 & -0.316 \\
Improve living standards & 0.534 & -0.648 & 0.360 & 0.136 & 0.570 \\
For Friends & 0.571 & 0.456 & -0.010 & -0.317 & -0.278 \\
Respect for others & 0.572 & 0.005 & -0.005 & -0.435 & 0.603 \\
Prove yourself & 0.588 & 0.403 & -0.110 & -0.021 & 0.276 \\
For employment & 0.605 & -0.017 & 0.468 & 0.019 & 0.127 \\
Troubleshooting mood & 0.609 & -0.312 & -0.070 & 0.410 & 0.208 \\
For the family & 0.646 & -0.307 & -0.489 & -0.064 & 0.233 \\
Enrich their lives & -0.010 & 0.162 & -0.168 & 0.004 & 0.724 \\
\hline
\end{tabular}

5) The component "Exercise" (0.467), reflecting the athletes by sports training to achieve physical fitness purpose. Therefore, this factor is named "Exercise factor".

\subsubsection{Female Disabled Athletes}

From Table 3, we can see that there are 5 characteristic values greater than $1(>1)$, so the extraction of 5 principal components shows in Table 4.

1) The component "Improve living standards" of variable factor 1 (0.992) associated with the highest coefficient, reflecting the female athletes with disabilities want to be able to improve the current living standards through participation in sports and improve their quality of life. Therefore, this factor is named "Substance pursuit factor”.

2) The component "For Travel" of variable factor 2 (0.908) associated with the highest correlation, reflecting the desire of female athletes think through their own efforts to win honor for disabled person. Therefore, this factor was named "Broaden horizons factor".

3) The component "Prove yourself" of variable factor 3 (0.786) associated with the highest coefficient, reflecting the female athletes with disabilities want to broaden their horizons and increase their knowledge. Therefore, this factor is named "Self-realization factor".

4) The component "Exercise and cater for their own interests" of variable factor $4(0.740 / 0.739)$ associated with the highest coefficient, reflecting the female athletes with disabilities want to enhance their physical fitness, 
Table 3. Main components of female athletes training motivation, contribution rate.

\begin{tabular}{ccc}
\hline Main Ingredients & Characteristic Value & The Contribution Rate (\%) \\
\hline 1 & 6.154 & 32.843 \\
2 & 4.253 & 19.753 \\
3 & 2.289 & 18.424 \\
4 & 1.534 & 10.275 \\
5 & 1.214 & 8.128 \\
6 & 0.897 & 6.267 \\
7 & 0.882 & 5.631 \\
8 & 0.791 & 4.813 \\
9 & 0.754 & 4.025 \\
10 & 0.628 & 3.835 \\
11 & 0.399 & 1.296 \\
12 & 0.125 & 1.235 \\
\hline
\end{tabular}

Table 4. Female athletes’ training motivation principal component features.

\begin{tabular}{cccccc}
\hline Component & Feature Vector 1 & Feature Vector 2 & Feature Vector 3 & Feature Vector 4 & Feature Vector 5 \\
\hline For Travel & -0.152 & 0.056 & 0.278 & 0.206 & 0.908 \\
Cater for their own interests & 0.074 & 0.617 & 0.368 & -0.059 & 0.739 \\
Glory for the country & 0.196 & 0.770 & 0.129 & -0.253 & 0.167 \\
For the family & 0.230 & 0.499 & -0.037 & 0.295 & 0.729 \\
Prove yourself & 0.291 & -0.084 & 0.019 & -0.374 & 0.786 \\
Respect for others & 0.308 & 0.685 & -0.158 & 0.387 & 0.420 \\
For Friends & 0.312 & 0.718 & -0.540 & 0.190 & 0.103 \\
Exercise & 0.342 & 0.591 & 0.303 & -0.069 & 0.741 \\
No purpose & 0.376 & 0.215 & 0.622 & -0.42 & -0.043 \\
To Account & 0.562 & 0.582 & -0.159 & -0.438 & -0.119 \\
Enrich their lives & 0.703 & -0.312 & -0.103 & 0.118 & 0.415 \\
To the university & 0.713 & 0.489 & -0.307 & -0.194 & 0.173 \\
For employment & 0.738 & -0.448 & 0.259 & 0.333 & -0.021 \\
Leaving the poor Environment & 0.788 & -0.324 & 0.349 & -0.276 & -0.174 \\
Improve living standards & 0.808 & -0.326 & 0.352 & 0.670 & 0.171 \\
\hline
\end{tabular}

and sports have deep feelings. Therefore, this factor is named "Exercise factor".

5) The component "For the family" of variable factor 5 (0.729) associated with the highest coefficient, reflecting the female athletes with disabilities want to reduce the burden from his family's life, psychological, economic and other aspects. Therefore, this factor is named "Family pressure factor".

\subsection{Motivations of Different Gender Athletes}

Through statistical data of the above, we can draw motivation of men and women athletes with disabilities to participate in sports there is a big difference (Table 5). So, why such differences exist, and the reasons behind that? We need are the characteristics of men and women athletes with disabilities in-depth analysis.

\subsubsection{Male Disables of Sports Participation Motivation}

First, enrich their lives. Due to facility limitations physical disability, mental inferiority and limited economic 
Table 5. Motivations of different gender athletes to participate in sports.

\begin{tabular}{ccc}
\hline \multirow{2}{*}{ Main Ingredients } & & Motivations \\
\cline { 2 - 3 } & Male & Female \\
2 & Enrich their lives & Improve living standards \\
3 & Contribute to the cause of disabled & For Travel \\
4 & Improve living standards & Prove yourself \\
5 & Exercise & Exercise and cater for interests \\
\hline
\end{tabular}

conditions and other factors, as well as our country specialized sports activities disabilities very unsound, that most people with disabilities are always locked in their own enclosed space, the contact The environment is very simple, life is more tedious. The survey found that in male athletes with disabilities, only 10.67 percent from urban areas, the majority of male athletes with disabilities before engaged in professional table tennis training come from towns and rural living environment conditions limit their lifestyle? After he engaged in professional training, by coaches and doctors care and attention, they can in the training process and gradually realize the growth and happiness. While professional sports training very hard, but for them to open a door leading to the community, so that they can come into contact with more people and things never encountered in training and competition and from all over, add your own experience and experience (Liu Feng et al., 2008). It is this life to avoid closure, growing desire for normal reasons, so that they are willing to adhere to day after day of hard training down and use it for fun.

Second, contribute to the cause of disabled. In the process of communicating with the object of investigation, we found that they did not know that this was a successful way before they did not engage in table tennis training. Because of the news of the block, the low level of culture, many people with disabilities have become a burden to the family, life in the village. Compared with women with disabilities, male disabled athletes more to the table tennis as a career, hoping to work through their own hard work, the success of the cause, but also for more people like him to do an example, you can copy his success along this path. Through their efforts, not only in the field has made remarkable achievements, for the country and individual to win the honor. Also, many outstanding disabled athletes through the broken shell admission, into the ideal university, to accept a higher level of cultural education, and then make their own people with disabilities to a higher level (Zheng, 2008). In the survey also found that the same age of male disabled athletes are more mature than women, more responsible, the attitude of the training is more serious. "I'm a real big man!" Male disabled people with perseverance and energy told me "why do you want to participate in sports?"

Third, improve living standards. Generally speaking, disability associated with poverty. As a man, the idea of traditional impact requirements must be for his own family to become the mainstay of the family. In the moment, however, under the condition of insufficient employment contribute to the cause of disabled, women disabled people rarely have fixed work, so the men become the creator of the family the main economic source contribute to the cause of disabled. So, they choose to engage in sports industry has become a way to change the condition of his own fate, and family. In all respondents, families living in poverty accounted for $64.8 \%$ of disabled athletes, athletes in the majority of men, only $24.5 \%$ of the men athletes in training has its own permanent job and income, if they can create a better performance, can you win more bonuses, let his family live a better life. After retirement, also can get very good settlement, assign a good jobs, and even can be arranged to some developed city.

Fourth, many of the disabled athletes surveyed the initial motivation comes from physical fitness, participating in sports activities to improve their physiological function. These disabled sport as to improve their body function, hone the will of the spirit means, make oneself have disabled body in maximize the strong. This kind of sports motivation seemingly ordinary, but from the Angle of psychology, this not the starting point of utilitarianism is the best motivation the lifelong sports habits (Wu Ke, 2013). In the survey found that some athletes physical disabilities are caused by the day after tomorrow, in the process of recovery after amputation, tentatively through a variety of sports activities to improve physical fitness, finally found himself like table tennis and insist on down. This is not only to enhance the physiological function, but also learn a function and find a momentum to continue living. 
Fifth, hope to get affirmation from others. Rejection of imperfect things is a primitive human instinct. It also makes people with disabilities in all aspects of life are able to feel the pressure of healthy people. Whether it is school, work or other aspects, they can feel not enjoy the same treatment with healthy people. Especially men with disabilities, social survival and family roles of pressure to make them more eager to succeed, and they can get social recognition. Therefore, in the training process, they are more than able-bodied people work hard and strive for their requirements more stringent, more intense desire to win the game. However, it is noteworthy point is that when athletes with disabilities in the face of competition when losing more prone to negative inferiority, the impact on the normal life and training will be. Thus, for disabled athletes timely scientific psychological counseling is necessary, not only to rebuild their confidence in life, and be able to make them out of the shadow of defeat as soon as possible, to face the difficulties and realities, in order to successfully continue its efforts under the time.

\subsubsection{Female Disables of Sports Participation Motivation}

First, pursuit material reward. Compared with male athletes pay more attention to life prospects, female athletes pay more attention to the immediate material reward. In the survey found, there are no female athletes with disabilities in addition to training a fixed income, one of the reasons for this is the immediate material reward female athletes more value, and 80 percent of female athletes to express their economic conditions after attending training camp has been improvement. Through interviews with female athletes with disabilities is understood that in the training process, not only to get daily training allowance, and after achievements, the government or sports management department will give a certain amount of economic incentives, and the more outstanding achievements, given the higher the bonus. It has no fixed income for female athletes, the hard work of training, for better rankings is to improve the living standards of the current own driving force (Qun and Li, 2011). Through the survey also found that compared with their peers male athletes, female athletes daily consumer items more, this is the motivation of female athletes are more inclined to pursue the matter lies.

Second, enrich their knowledge. After the table tennis training, through their own efforts, in the form of training, communication, competition and other activities, had more broaden horizons, enrich their knowledge, the chance to visit the world. Especially for disabled female athletes, this kind "the world is so big, I want to see" the psychology is more apparent, especially those that can be opportunities to other countries in the competition, is undoubtedly a great temptation to them. According to the study of female athletes, they think visit fun attractions, shopping and making new friends is that they go out time favorite three things (Yu et al., 2009). For them, table tennis is not just a they engage in sports activities, but also a ticket through all over the world; In order to be able to get the number of the few tickets, they will pay a very hard work.

Third, realize their value. In Chinese traditional concept, social success or failure of women reflects the attitude of tolerance, which also makes socially acceptable pressures faced by female athletes than male athletes to small, women with disabilities, it is possible through the efforts of its own career success, reflecting the value of their own existence is even more valuable. For example, like China's Zhang Haidi, as well as the United States of Helen Keller. However, these disabled women athletes do not like to give charity and compassion on social morality, more attention through hard training to surpass themselves through achievements, won the race to succeed feelings in such a way to prove that although his body has disabled but you can still be successful in certain areas, but also to sound like everyone else, can reflect the social value of their own existence (Zhang Liwei, 1988). Female athletes and male athletes of different, they just want to prove themselves, rather than utilitarian to give the corresponding social status and recognition.

Fourth, strengthen physical health, satisfy the hobby. As with male athletes, female athletes also have the purpose of through training to improve body function. Show the female athletes also want to make up contribute to the cause of disabled physical weakness through training, avoid because of residual and waste. And different from male athletes, female athletes in addition to want to be able to maintain a healthy body, more hope through training can keep good shape, it also embodies the disabled women athletes heart of beauty. On the other hand, $85 \%$ of the women athletes said he insisted on table tennis, long-term training because I genuinely love this sport. They day accompany with table tennis, table tennis has become an integral part of their lives. As a female said: "there is no table tennis training before, she just have tone in alive; and with table tennis, she only lived a real life." According to their basic data shows that $35 \%$ of female athletes to participate in the training has been more than five years, there are three people has reached 10 years of training time, it was also in this kind of love that makes them able to constantly insist and progress. 
Fifth, ease the family pressure. The appearance of the deformity not only brings the physical and psychological pain to the disabled, but also makes the family have a heavy economic and psychological burden, especially for women with disabilities is a weak social vulnerable groups, but also make the family more excellent for their future life. In addition to most women with disabilities after marriage dependent on their partner's financial support, to bring pressure on the family economy, while women for the inconvenience brought his family often are more sensitive to the so when exercise training can reduce the economic pressure, to the family of self-reliance may be, they will seize this opportunity to reduce the family burden. On the one hand, the active participation of women with disabilities in the training of the family can let the family in a psychological way to get some comfort, they can also like a healthy person to integrate into the community. On the other hand, training grants can ease the economic pressure on the family, which is a contribution to the family.

\subsection{Analysis of Male and Female Differences in Disabled Sports Participation Motivation}

As shown in Figure 1, the male and female persons with disabilities to participate in sports activities motive, there are similarities but also differences:

1) "Improve living standards" and "physical fitness" is bisexual athletes have strongly endorsed the participation of motivation. It reflects a strong sense of responsibility this group of athletes and a strong desire to improve their level of physical function. From a psychological goal orientation and internal and external motivation theory, this motivation is the most balanced, not only focus on the sport itself, internal motivation, external motivation but also bear responsibility for the social and family life, and perhaps in this official It supported a group of multiple motive excellent table tennis players with disabilities for many years of hard training.

2) The existence of gender athletes more significant difference between internal and external motivation in other areas: Motivation male athletes are mainly internal motivation, such as: In order for disabled persons, rich life, to win the respect of others, and so on. Motivation female athletes more performance for external motivation, such as: the pursuit of material increases their knowledge, relieve family stress, and so on. After a review of other literature, to improve people, male and female athletes of sports participation motivation there is such a difference. But for disabled athletes such a special group, this difference in internal and external motivation is more magnified. This also shows that male athletes with disabilities more rational, more full of perseverance and sense of responsibility, hoping to improve their families and at the same time contribute to society; women with disabilities are more expect to receive external rewards or returns, which may be female athletes background of life and more emotional psychological characteristics related.

3) For the "long-term interests" and "immediate interests", difference gender athletes have different understanding. Male athletes pay more attention to long-term benefits in return: they expect to achieve good race results through their own efforts, they can give their future career bring better security, but also for the way out after retirement to prepare. While female athletes with disabilities pay more attention to the immediate interests, such as: improving the standard of living, traveling around the world, reducing the burden on the family, and so on. This motivation difference did not vary, but by the social roles of different genders decision. Male athletes in the trainees and the game had to consider a more long-term way out of the problem, as well as their ability to

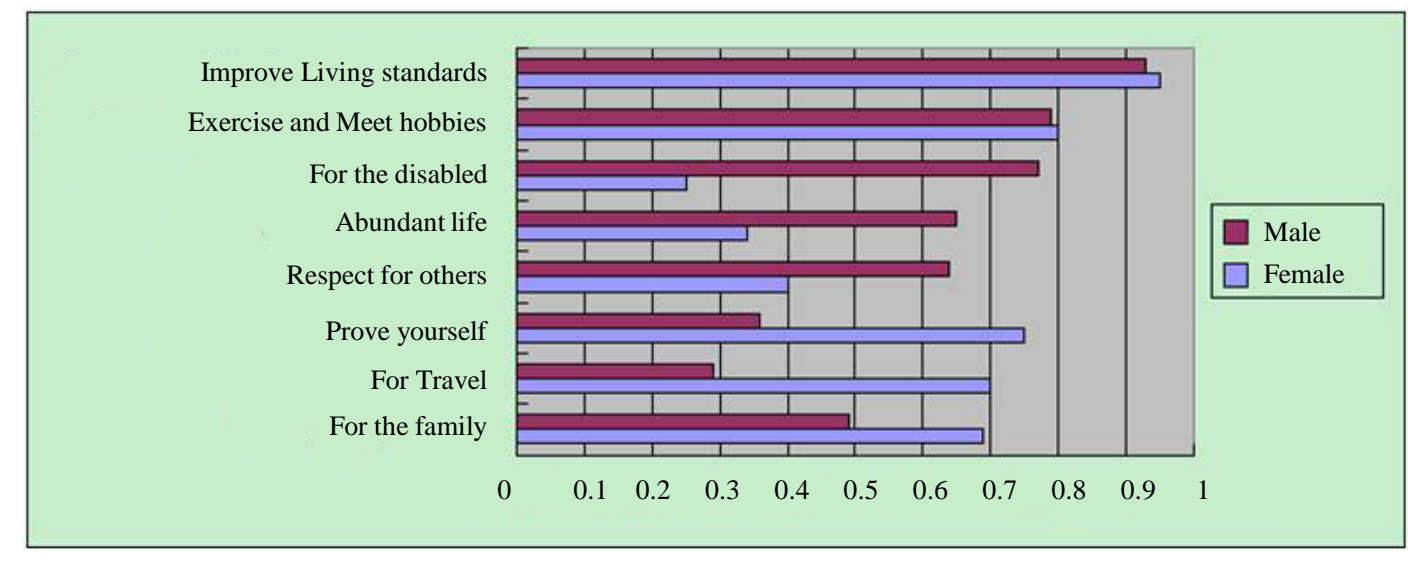

Figure 1. Comparison of participation in sports motivation of male and female persons with disabilities. 
assume the dual responsibility to better the family and society.

\subsection{Other Factors Affecting the Sports Participation of Disabled Persons In Addition to Gender}

\subsubsection{Age}

In addition to gender factors, the greatest impact on the sport participation of the disabled persons is the most influential factor. The survey of the disabled athletes in the age range of 14 - 41 years old, the age span is larger. In view of this, the 14 - 18 years old and 18 years of age and older persons with disabilities were distinguished, referred to as the "minor group" (35) and "adult group" (48) two parts. Because of the age of the disabled athletes, although there are many years of table tennis training experience, but because of the reasons, the motivation to participate in table tennis training is still a big difference between adults. Embodied in two aspects:

On the one hand, the disabled athletes filled out the "Questionnaire of Motivation Adapted Athletes (AQAM)", since each set of problems are divided into five levels, with 1 being the lowest score, 5 being the highest score. Through effective questionnaire survey feedback disabled athletes, the "minor group" select "extreme value" in the questionnaire is much higher than the proportion of "adult" (Note: "extreme value" means the 1 minute or 5 points). In other words, the younger, the attitude of too paranoid perception of things, not yet formed a relatively stable psychological characteristics. For the "adult" disabled athletes, along with training and competition time accumulated experience, knowledge of the sport of table tennis is more comprehensive and stable judgment of things some of the more robust.

On the other hand, from the dimension of internal motivation and external motivation, the underage athletes with disabilities are more focused on the immediate material rewards, game play and other external stimuli, more attention to the coach, the players evaluate their own; relatively speaking, adult athletes, especially some of the old players, their motivation to participate in table tennis training more from their own love and for their loyalty to the cause of the ping-pong movement. In view of this, people with disabilities often appear in minor sports participation in significant mood swings, poor athletic performance stability, the need for more counseling and care education.

\subsubsection{Family Economic Conditions}

People involved in sports, especially persons with disabilities to participate in sports, especially into the field of professional sports, are the need for certain economic base as a support. In the survey, about $80 \%$ of the respondents were from the city, the family economic level is better, less than 20 percent of the respondents were from rural areas, more difficult family economic level. This also shows that China's current efforts to support people with disabilities, particularly people with disabilities in rural areas still do not get attention and become the social development of marginalized groups. In addition, people with disabilities are still more limited sports development in the more developed cities, the rural disabled sports is also still in the embryonic stage of development, the needs of social welfare policy and sports policy to rural areas, increase support for farmers sport, taking into account people with disabilities other sports needs of special groups.

Through questionnaires and interviews with feedback information indicates that although the small number of disabled athletes from rural areas, but the effort is the highest level of sport more prominent. Their internal motivation and external motivation is very strong, it is this sense of professionalism and sense of responsibility, that makes them superior to others rural disabled athletes sports results.

\subsubsection{Education Level}

Generally speaking, a person's level of education reflects the person's educational situation, also reflects whether the good cultural accomplishment. For athletes with disabilities, receive a better level of education is not only good for future employment after retirement security is more important to be able to lay the foundation for the comprehensive development of man. In this investigation, the primary education of athletes for 18 people (21.7\%), high school graduates to 42 people (50.6 percent), college educated and 21 (25.3\%), graduate and above for 2 people (0.02\%).

Through surveys and interviews found that the higher the education level of athletes, the quality of the completed questionnaires, the better, fill out the questionnaire and more serious attitude, subsequent interviews and more harmonious; In contrast, some without college education The disabled athletes, although the effective 
completion of the questionnaire, fill out the bad attitude, even with its friendly exchanges cannot be carried out. On the other hand, the motivation for participation, the higher the education level, the more emphasis on long-term development, internal motivation is more obvious; the lower the education level, the more concerned about immediate gains and losses, external motivation is more significant (Wu and Huang, 2007).

\subsubsection{Training Time}

In the normal range of motion, the athletes' technical level is proportional to the length of the athletes' movement. That is to say, although the success of athletes have a certain relationship with the talent, but the day after day training is the important guarantee of success. In this study, the training time athletes in 2 months to 21 (25.3\%), 2 months to 1 year of athletes for the nine people (10.8\%), in years 1 to 5 athletes for 16 (19.3\%), 5 years to 10 years of athletes for 24 (28.9\%), the athletes for more than 10 years to 13 (15.7\%).

In the survey found that years of training in the internal motivation of athletes for more than 5 years to 10 years the most stable, understanding of table tennis career, more rational and comprehensive. And the different movement duration less than 5 years, especially just into the training of the new players, to table tennis is very simple, the participation motivation is more reflected in the queue of welfare benefits (Wu and Huang, 2008). The difference is that the sports life of the longest, the highest level of the overall movement of the " 10 years or more”, the questionnaire reflects strong external motivation, pay more attention to the quality of life requirements, the value of each game's reward. Through the follow-up to his (her) who were interviewed to know that many of them are about to retire, for the future life of the consideration, the idea emerged.

\subsubsection{Degree of Disability}

The difference between disabled and healthy people in the sport is that people with disabilities are divided according to the degree of disability to ensure the fairness of the game. In the table tennis match of the disabled, there are 10 grades (TT10-TT1). Among them, the "TT1-TT5" on behalf of the sitting position, “TT6-TT10”, said the level of standing posture. TT6 and TT1 indicated that the highest degree of disability in the sitting and standing posture, while the TT10 and TT5 indicated that the degree of disability was the lowest (Xiong et al., 2005).

There is a special factor in the disabled athletes, because of the difference in the degree of disability caused by a certain difference. In the survey found that the degree of disability (TT1-TT3, TT6-TT7) of the athletes, the difference between internal motivation and external motivation is more obvious. There are a part of the high disabled athletes are enjoying the current pace of this training and competition, but there are a part of the high disabled athletes are very clear that the table tennis is to better their better life, in order to improve the situation of the family. The difference between the internal motivation and external motivation of athletes in the lower level of the athletes is relatively low.

\section{Suggestions for the Disabled Athletes}

\subsection{Strengthen Psychological Guidance and Cultural Education of the Disabled Athletes}

In the course of the investigation, we can deeply feel the tenacity and perseverance of the disabled table tennis players, and their dedication to the training brings great shock to our researchers. However, through the investigation and visit, disabled athletes need more than just external stimulus, and more attention should be paid to improving the inner culture and the cultural and moral level. Many disabled athletes' sports level is very high, and they have achieved good results, but they have difficulties in interpersonal communication. In the eyes of some athletes, their only task is to practice the ball. Some excellent athletes take it for granted that they come from the service of their players and they do not respect others. Therefore, it is essential to strengthen the culture and moral education of the elite disabled athletes. "Especially for athletes with a higher degree disability, their pay is unimaginable, but it is also more prone to psychological problems. Therefore, the coach's humanistic care to the disabled people is the important link to improve the performance of sports training. Chinese champion coach Yuan Feng said: "for the people with disabilities to participate in sports, the most essential purpose is not purely for gold, but for a healthier and more comprehensive education”.

\subsection{Male and Female Disabled Athletes should be Treated Differently}

In addition, through this research, we can find that the factors affecting the sports participation motivation of the 
disabled persons are many dimensions and many aspects, and the main influencing factors are gender factors, which is also the focus of this study. The training and management approaches of different genders should be treated differently and the problem also should be targeted to distinguish between treatments. But on the current table tennis training base, the men and women use a set of training mode, a coach team, a shared training venue, which is the highest level of the Chinese people with table tennis players, it seems not too scientific. Compared with the scientific and systematic management training mode of Chinese table tennis team, the Chinese Paralympic table tennis team is too rough and shabby and even squad training of men and women cannot be achieved. From the perspective of modern sports, the training and management of sports teams pay more attention to the details of each athlete. This era requires excellent athletes who have their own unique ability to judge and solve the ability. Scientific instruction and humanized management is an important measure to improve the level of physical education for the disabled. If you are still using the old training methods, athletes are likely to go astray. Therefore, paying attention to the psychological problems of the disabled athletes becomes an important issue in this field. In addition, from the microscopic point of view, the coach must have a certain psychological adjustment and guidance of scientific method, and must be familiar with each athlete's personality characteristics and sports level. This can not only increase the athletes' psychological adaptation strength, but also be able to understand the psychological fluctuations (especially female athletes) caused by various aspects of the psychological intervention, to protect the disabled athletes' training and competition.

\subsection{To prevent the Loss of the Sports Population of the Disabled}

Everything has two sides, when this study is to explore "why do people want to participate in sports", but also there is "why do people want to leave the sport", that is, the problem of the loss of sports population. In order to make more people with disabilities to participate in physical training, we must not only understand the current active participation of disabled athletes, but also understand what does not carry out the idea of sports training for the disabled. Through the investigation of this study, disabled sports population that is easy to lose the object is mainly concentrated in the following three groups: young disabled athletes (12-14 years old); just enqueue athletes (training time in two months); the female athlete.

\section{Limitations of This Study}

The research objects of this study are the disabled athletes in table tennis training base of Shandong Normal University. They are a small sample, and cannot fully reflect the status quo of the sports participation of all persons with disabilities, and cannot completely reflect the attitude of all the disabled people, which is a major limitation of this study. In addition, we choose table tennis the athletes because table tennis in China has great mass base and the results of Chinese disabled table tennis projects in the international contest are prominent. National Paralyzing tennis training base is on the campus of Shandong Normal University, so it is easy to lock to carry out research work and subsequent interviews of the object. However, there are still some limitations in this study. The disabled athletes investigated in this study are table tennis players and there are no athletes of other items because of the limited capacity and energy of the researchers, which may result in the deviation of the analysis results. In addition, the research is mainly reflected the training motivation of the disabled athletes, the lack of other psychological indicators of the analysis may also make the conclusion of this study not objective and fair.

\section{References}

Liu, F., He, J., \& Tang, W. D. (2008). On the Development and Protection of the rights Of the Disabled sports. Shandong Institute of Physical Education, 12, 30-33.

Qun, J. X., \& Li, Y. H. (2011). Shandong Social Security and the Social Security Needs of Rural People with Disabilities. Population Journal, No. 3, 53-60.

Wu, Y. D., \& Huang, H. S. (2007). Influence of Beijing Paralympic Games on Chinese Sports for Disabled. Wuhan Institute of Physical Education, 41, 31-34.

Wu, Y. D., \& Huang, H. S. (2008). Integration and Sharing: Harmonious Perspective Disabled Sports Sustainable Development. Sport Science, 28, 9-15. 


\section{J. D. Zhou et al.}

Wu, K. (2013). American Sports Organization Contribute to the Cause of Disabled Study. Beijing: Beijing Sport University Press.

Xiong, L. H., Li, T. Z., \& Yang, Q. (2005). On the Fitness of Persons with Disabilities and Social Mobilization Social Constraints. Beijing Sport University, 28, 1309-1311.

Yu, J., Li, Y. X., \& Sun, M. J. (2009). Shandong Province Disabled Sports Present Situation and Development Countermeasure Research. Sports Science, No. 8, 65-72, 89.

Zheng, G. C. (2008). Social Security of Persons with Disabilities: Status and Development Thinking. People's University of China, No. 1, 2-9. 